\title{
Sulcus Centralis
}

National Cancer Institute

\section{Source}

National Cancer Institute. Sulcus Centralis. NCI Thesaurus. Code C33654.

A prominent furrow or groove in the cerebral cortex that divides the frontal lobe from the parietal lobe in the coronal plane, which demarcates the primary motor and somatosensory areas of the cortex. 